\title{
Management Pathways for Dysuria: Recurrent UTIS
}

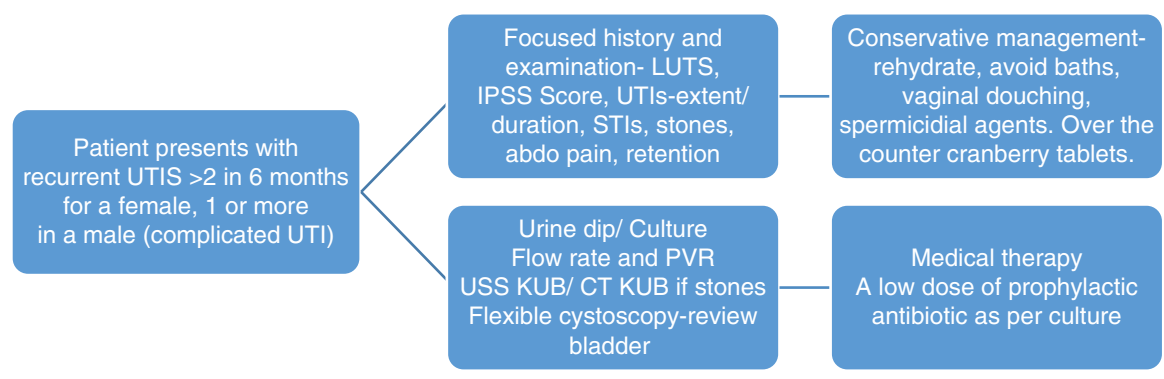

\section{Suggested Reading}

Michels TC, Sands JE. Dysuria: evaluation and differential diagnosis in adults. Am Fam Physician. 2015;92(9):778-86.

Naber KG, Bergman B, Bishop MC, Bjerklund-Johansen TE, Botto H, Lobel B, Jinenez Cruz F, Selvaggi FP. Urinary Tract Infection (UTI) Working Group of the Health Care Office (HCO) of the European Association of Urology (EAU). EAU guidelines for the management of urinary and male genital tract infections. Urinary Tract Infection (UTI) Working Group of the Health Care Office (HCO) of the European Association of Urology (EAU). Eur Urol. 2001;40(5):576-88.

Johansen TE, Botto H, Cek M, Grabe M, Tenke P, Wagenlehner FM, Naber KG. Critical review of current definitions of urinary tract infections and proposal of an EAU/ESIU classification system. Int J Antimicrob Agents. 2011;38:64-70. 